\title{
Producción de pan de abejas (Apis mellifera L.) bajo condiciones de laboratorio
}

\author{
Bee bread production (Apis mellifera L.) under laboratory conditions
}

\author{
Ximena Araneda $^{1 *}$, Carmen Velásquez ${ }^{1}$, Daniza Morales $^{1}$, Isabel Martínez $^{1}$
}

\begin{abstract}
RESUMEN
El objetivo de este trabajo fue fabricar pan de abejas bajo condiciones de laboratorio a partir de sus ingredientes constitutivos por medio de procesos fermentativos evaluando sus características bromatológicas. Para ello se extrajo pan de abejas como inóculo desde panales de Apis mellifera para la fermentación del polen con miel. El ensayo estuvo constituido por seis tratamientos con tres repeticiones cada uno. Los tratamientos fueron: $\mathrm{T}_{0}$ : polen sin inóculo, $\mathrm{T}_{1}:$ pan de abejas natural, $\mathrm{T}_{2}$ : polen $+5 \%$ de inóculo, $\mathrm{T}_{3}$ : polen $+10 \%$ de inóculo, $\mathrm{T}_{4}$ : polen $+15 \%$ de inóculo, $\mathrm{T}_{5}:$ polen $+20 \%$ de inóculo. Cada tratamiento fue colocado en frascos estériles con polen, inóculo y una capa de miel. En las evaluaciones se midió la cantidad de ácido láctico, pH, acidez, MS, ceniza y proteína cruda. El contenido de ácido láctico al final de la evaluación fue menor en el tratamiento $\mathrm{T}_{1}$ con un promedio de $0,22 \%$, mientras que $\mathrm{T}_{0}$ obtuvo el valor más alto de ácido con $0,47 \%$. En cuanto al $\mathrm{pH}$, todos los tratamientos tendieron a acidificarse con el tiempo, siendo $\mathrm{T}_{0}$ el que obtuvo el valor más bajo $(3,83)$. El porcentaje de acidez aumentó cerca de un punto para todos los tratamientos, principalmente $\mathrm{T}_{5}$, siendo el más similar al pan de abejas natural en la última medición, con 4,83\% de acidez. Los valores de MS en general disminuyeron entre $1 \%$ y $5 \%$, y la cantidad de cenizas obtuvo bajos valores, pero similares a lo citado en la literatura, mientras que los contenidos de proteína cruda de todas las muestras analizadas fueron buenos, con valores sobre el 20\%. Por lo tanto, es factible elaborar pan de abejas en laboratorio, pero es necesario conocer las proporciones y características de elementos que las abejas adicionan a este, para una correcta formulación del producto.
\end{abstract}

Palabras clave: polen, polen acidificado, ácido láctico, fermentación.

\begin{abstract}
The aim of this study was to make bread of bees under laboratory conditions from its constituent ingredients through fermentation processes assessing their qualitative characteristics. This bee bread as inoculum extracted from combs of Apis mellifera for fermentation of pollen and honey. The test consisted of six treatments with three replicates. The treatments were: $T_{0}:$ pollen without inoculum, $T_{1}$ : natural bee bread, $T_{2}$ : pollen $+5 \%$ inoculum, $T_{3}$ : pollen $+10 \%$ inoculum, $T_{4}:$ pollen $+15 \%$ inoculum, $T_{5}:$ pollen $+20 \%$ inoculum. Each treatment was placed in sterile flasks with pollen, inoculum and a layer of honey. Evaluations the amount of lactic acid, $\mathrm{pH}$, acidity, MS, ash and crude protein was measured. The content of lactic acid at the end of the evaluation was lower in the treatment $T_{1}$ with an average of $0.22 \%$, while $T_{0}$ obtained the highest value of $0.47 \%$ acid. As the pH all treatments tended to be acidified with time, being $T_{0}$ which had the lowest value (3.83). The percentage of increased acidity near a point for all treatments, mainly $T_{5}$ being the most similar to natural bee bread in the last measurement with $4.83 \%$ acidity. MS values generally fell between $1 \%$ and $5 \%$, and the amount of ash obtained low values, but similar to the literature cited above, while the crude protein content of all samples were good, with values about $20 \%$. Therefore, it is feasible to make bread bee lab, but you must know the proportions and characteristics of elements that bees added to it, for a correct formulation of the product.
\end{abstract}

Key words: pollen, pollen acidified, lactic acid, fermentation.

\section{Introducción}

El pan de abejas es polen almacenado parcialmente fermentado que las obreras mezclan con sus propias enzimas digestivas (Nagai et al., 2004) y que almacenan en las celdillas agregando una capa de miel como única fuente de carbono (Audisio et al., 2004). Esto, al quedar sellado y en los panales adyacentes a la cámara de cría $\left(35^{\circ} \mathrm{C} \mathrm{a} 36^{\circ} \mathrm{C}\right)$, sufre una serie de transformaciones, debido a la acción de diferentes enzimas, como esterasas, lipasas, proteasas, aminopeptidasas y fosfatasas que hacen al pan de abejas más digerible (Gilliam et al., 1990; Dustmann, 2007), que junto a otros microorganismos,

\footnotetext{
1 Escuela de Agronomía, Facultad de Recursos Naturales, Universidad Católica de Temuco, Rudecindo Ortega 02950, Temuco, Chile.

* Autor para correspondencia: xaraneda@uct.cl
}

Fecha de Recepción: 4 Julio, 2014.

Fecha de Aceptación: 28 Agosto, 2014. 
bacterias ácido lácticas, humedad y temperatura; permiten la conversión, mejoramiento y preservación del polen almacenado (Gilliam et al., 1990; Audisio et al., 2004), el que después de dos semanas se convierte en pan de abejas (Loper et al., 1980; Asis, 2001; Dustmann, 2007), adquiriendo determinadas propiedades organolépticas que contribuyen a mejorar la conservación, manteniendo la tasa de digestibilidad del polen constante a lo largo del año (Oliveira et al., 2002).

El pan de abejas está compuesto de proteínas, carbohidratos, lípidos, minerales, vitaminas, varios ácidos orgánicos, enzimas y otras sustancias (Chmielewski, 2006), es rico en vitaminas E, del complejo B, carotenoides (provitamina A), aminoácidos esenciales y ácidos grasos (Asís, 2001; Dustmann, 2007); y posee notables cualidades antioxidantes (Nagai et al., 2004), existiendo una buena correlación entre el contenido de fenoles totales y su capacidad antioxidante (Stanciu et al., 2007). Por esta razón, el pan de abejas es mucho más rico que el polen en su composición (Dustmann, 2007), ya que además el azúcar y agua de la miel son absorbidas poco a poco por las células del polen, las que luego estallan por shock osmótico, lo que libera al citoplasma de su interior haciendo digeribles los aminoácidos y antioxidantes contenidos en él (Dustmann, 2007). Razón por la que este se usará cada vez más como suplemento alimenticio debido a sus propiedades antioxidantes, mayores a las de la miel (Baltrusaityte et al., 2007), propiedades antibióticas y gran aporte nutricional que triplica al del polen corbicular, que además de poseer las cualidades biológicas del polen, eleva las propiedades inmunológicas, mejora la capacidad de adaptación del organismo, contribuye a disminuir la fatiga y juega un papel importante en la alimentación dietética (Asís, 2001). Además, estudios de Nagai et al. (2005) revelan que hidrolizados enzimáticos de pan de abejas son de beneficio no solo desde el punto de vista nutricional, sino también de salud, por ejemplo en diversas enfermedades como el cáncer, enfermedades cardiovasculares, diabetes e hipertensión.

Sin embargo, a pesar que el pan de abejas es mucho más rico que el polen en su composición, es más difícil para extraer desde los panales (Dustmann, 2007), además, la destrucción de los panales es inherente a la extracción manual del pan de abejas, incluso con pérdidas considerables de nutrientes (Akhmetova et al., 2012). Por todo lo anterior, y por ser el pan de abeja un producto de origen natural, con potencialidades de mercado, y una rica fuente de proteína vegetal altamente asimilable y con antioxidantes; pero con dificultades de extracción desde los panales y, como consecuencia lógica de ello, de muy difícil aprovechamiento, se plantea la posibilidad de fabricar pan de abejas bajo condiciones de laboratorio a partir de sus ingredientes constitutivos por medio de procesos fermentativos evaluando sus características bromatológicas en laboratorio.

\section{Materiales y Métodos}

La presente investigación se realizó en el Laboratorio de Sanidad Vegetal y de Bromatología de la Escuela de Agronomía de la Universidad Católica de Temuco.

Se extrajo muestras de pan de abejas desde colmenas del Apiario Experimental de la Universidad Católica de Temuco localizado en la Estación Experimental Pillanlelbún ubicado a $18 \mathrm{~km}$ al Norte de la ciudad de Temuco, Chile (38 39' 17,2" latitud Sur, $72^{\circ} 26^{\prime}$ 56" longitud Oeste). Estas muestras fueron colectadas mediante el retiro de panales y trasladadas en bolsas de polietileno hasta el laboratorio para su posterior uso como inóculo para formular pan de abejas artificial.

El pan de abejas se extrajo manualmente de las celdillas, se mezclaron todas las muestras con el fin de homogenizar su origen botánico; luego se montó el ensayo mezclando polen corbicular, con diversos porcentajes de inóculo procedentes de muestras frescas de pan de abejas. En las mediciones iniciales del polen y pan de abeja utilizados para inóculo se obtuvo en promedio $0,34 \%$ y $0,53 \%$ de ácido láctico, respectivamente, un $\mathrm{pH}$ inicial de 4,70 en polen y 3,72 en pan de abejas y $3,75 \%$ de acidez titulable en polen y en pan de abejas $5,4 \%$ de acidez titulable expresada como ácido láctico.

Se establecieron seis tratamientos con tres repeticiones cada uno, cuyas características se especifican en la Tabla 1.

Cada repetición se colocó en un frasco estéril, con polen e inóculo más una capa de $4 \mathrm{~g}$ de miel monofloral de borraja para impedir el ingreso de aire y así evitar pérdidas de oxidación y fermentaciones aeróbicas putrefactivas simulando el comportamiento de las abejas en el almacenamiento del polen (Elizalde et al., 1996). A continuación, todos los tratamientos con sus respectivas repeticiones fueron dejados en una estufa de incubación a $35^{\circ} \mathrm{C}$ para emular la 
Tabla 1. Tratamientos utilizados en el ensayo.

\begin{tabular}{ccccc}
\hline Tratamiento & Porcentaje de inóculo $(\%)$ & Cantidad de inóculo $(\mathrm{g})$ & Cantidad de polen $(\mathrm{g})$ & Cantidad total $(\mathrm{g})$ \\
\hline $\mathrm{T}_{0}$ & 0 & 0 & 30 & 30 \\
$\mathrm{~T}_{1}$ & 100 & 30 & 0 & 30 \\
$\mathrm{~T}_{2}$ & 5 & 1,5 & 28,5 & 30 \\
$\mathrm{~T}_{3}$ & 10 & 3 & 27 & 30 \\
$\mathrm{~T}_{4}$ & 15 & 4,5 & 25,5 & 30 \\
$\mathrm{~T}_{5}$ & 20 & 6 & 24 & 30 \\
\hline
\end{tabular}

Tabla 2. Ácido láctico de los tratamientos en el tiempo (\%).

\begin{tabular}{cccccc}
\hline Tratamiento & Día 0 & Día 5 & Día 10 & Día 15 & Día 20 \\
\hline $\mathrm{T}_{0}$ & $0,57 \mathrm{a}$ & $0,63 \mathrm{a}$ & $0,42 \mathrm{a}$ & $0,39 \mathrm{a}$ & $0,47 \mathrm{a}$ \\
$\mathrm{T}_{1}$ & $0,59 \mathrm{a}$ & $0,67 \mathrm{a}$ & $0,37 \mathrm{a}$ & $0,42 \mathrm{a}$ & $0,22 \mathrm{c}$ \\
$\mathrm{T}_{2}$ & $0,62 \mathrm{a}$ & $0,42 \mathrm{a}$ & $0,27 \mathrm{a}$ & $0,27 \mathrm{a}$ & $0,35 \mathrm{~b}$ \\
$\mathrm{~T}_{3}$ & $0,53 \mathrm{a}$ & $0,49 \mathrm{a}$ & $0,29 \mathrm{a}$ & $0,29 \mathrm{a}$ & $0,29 \mathrm{bc}$ \\
$\mathrm{T}_{4}$ & $0,42 \mathrm{a}$ & $0,48 \mathrm{a}$ & $0,26 \mathrm{a}$ & $0,34 \mathrm{a}$ & $0,28 \mathrm{bc}$ \\
$\mathrm{T}_{5}$ & $0,52 \mathrm{a}$ & $0,37 \mathrm{a}$ & $0,32 \mathrm{a}$ & $0,34 \mathrm{a}$ & $0,30 \mathrm{bc}$ \\
\hline
\end{tabular}

Cifras con letras diferentes en las columnas indican diferencias significativas entre tratamientos, según test de Tukey $(\mathrm{p} \leq 0,05)$.

temperatura de la cámara de cría. Posterior al montaje del ensayo se extrajo muestras de cada repetición en tiempo cero, y cada 5 días hasta completar 20 días.

Se midió y registró la cantidad de ácido láctico usando reflectómetro (RQ-Flex de Merck), con el método propuesto por Hanke (1998), con la salvedad de que se disolvía $1 \mathrm{~g}$ de muestra en $50 \mathrm{~mL}$ de agua debido a la gran cantidad de ácido láctico presente en las muestras. También se midió pH (potencial hidrógeno) y acidez titulable (expresada como ácido láctico al multiplicar por el factor 0,09 ), de cada una, para caracterizar su proceso de fermentación. Igualmente, se midió el porcentaje de materia seca (MS), cenizas, y proteína cruda (método Kjeldahl), para complementar la caracterización (Matissek et al., 1998) al inicio y al final del ensayo. Además, para estos parámetros a las muestras de polen y pan de abejas que sirvieron de inóculo para la formación de los tratamientos, también se les midió inicialmente el porcentaje de MS con valores de $85,44 \%$ y $74,98 \%$, en cenizas $3,21 \%$ y $3,17 \%$ y en proteína $33,14 \%$ y $25,54 \%$ en polen y pan de abejas, respectivamente.

Para el análisis estadístico de los datos, en los parámetros $\mathrm{pH}$, porcentaje de acidez expresada como ácido láctico y porcentaje de ácido láctico medido con reflectómetro se utilizó el programa estadístico SPSS, versión 15.0 para Windows, para el análisis de varianza (ANDEVA) se utilizó el test de comparación múltiple de Tukey y Tamhane ( $\mathrm{p} \leq$
0,05), y para las variables MS, cenizas y proteína cruda, se realizó estadística descriptiva.

\section{Resultados y Discusión}

\section{Ácido láctico}

En la Tabla 2 se aprecian los promedios de ácido láctico en cada tratamiento en el tiempo. Aquí se observa que en los primeros días de medición no se encontraron diferencias estadísticamente significativas $(p>0,05)$ en ninguno de los tratamientos. Sin embargo, en el último día de evaluación se presentan diferencias significativas entre los tratamientos, presentando el tratamiento $\mathrm{T}_{1}$ el menor contenido de ácido al final del proceso con un promedio de $0,22 \%$ de ácido láctico, mientras que $\mathrm{T}_{0}$ es el que obtuvo el valor más alto de ácido con $0,47 \%$. Lo que se corrobora con DeGrandi-Hoffman et al. (2013), quienes obtuvieron que el pan de abejas fue más ácido que el polen, y que además la acidez está influenciada por el genotipo, por lo que las abejas europeas producen pan de abejas ligeramente más ácido que las abejas africanizadas. Lo anterior tiene lógica, pues $\mathrm{T}_{0}$ es el tratamiento sin inóculo y por lo tanto el que tiene menos ácido láctico, en cambio $\mathrm{T}_{1}$ es el que contiene $100 \%$ de pan de abejas y consecuentemente el que contiene más ácido láctico. 
En general se observa que todos los tratamientos tienden a disminuir su cantidad de ácido láctico con el tiempo. Esto se explica porque las bacterias ácido lácticas operarían en las primeras etapas de fermentación, ya que después se ven inhibidas por la acidez del medio (producto del ácido láctico que ellas mismas generan), y comienzan a proliferar otras levaduras que son bastante tolerantes a la acidez, las que continúan el proceso hasta agotar los carbohidratos fermentables (Gilliam et al., 1989; Elizalde et al., 1996), que en este caso provienen de la miel añadida y del néctar con el que se aglutina el polen floral para hacer esferas de polen corbicular (Dustmann, 2007). La presencia de gran cantidad de ácido láctico con sus combinaciones, además de sus propiedades antibióticas, contribuye a la conservación del producto en buen estado, que en lugar fresco y seco puede durar hasta 17 años (Asís, 2001). De esta manera, en A. mellifera, la asociación de polen almacenado con los microorganismos responsables de la fermentación o predigestión de los alimentos permiten mejorar la digestibilidad del polen mediante la producción de algunas enzimas de estos microorganismos (Gilliam et al., 1990).

Por esta razón, el éxito del proceso fermentativo que ocurre en los ensilajes depende, principalmente, de una cantidad suficiente de bacterias ácido lácticas y de una concentración adecuada de carbohidratos solubles en el forraje que genera el ácido láctico (Villalobos, 2003), de allí la importancia de estudiar la calidad y cantidad de miel añadida, ya que la producción de pan de abejas es producto de la fermentación de la miel por la flora de bacterias ácido lácticas del estómago, añadida al polen por el néctar regurgitado del estómago (Vásquez y Olofsson, 2009).

\section{pH}

En general, se observa que todos los tratamientos tienden a acidificarse con el tiempo (Tabla 3), existiendo diferencias significativas entre los tratamientos $(\mathrm{p} \leq 0,05)$. En el día 0 solo se observan diferencias estadísticas entre $\mathrm{T}_{0} \mathrm{y}$ el resto de los tratamientos, donde $\mathrm{T}_{0}$ es el que obtuvo el $\mathrm{pH}$ promedio más bajo de todos. En el día 5, 10, 15 y 20 se observa que $\mathrm{T}_{1}$ y $\mathrm{T}_{2}$ tienen los promedios más altos. En el día 20, además, los promedios tienden a aproximarse, siendo $\mathrm{T}_{0}$ al igual que en el día 0 , el que obtuvo el promedio de $\mathrm{pH}$ más bajo.

En este sentido, Asís (2001) señala que al día 15 el pan de abejas alcanza un pH de entre 4 y 4,3, momento en el que el polen se transforma en pan de abejas (Nagai et al., 2004). Por ello se puede decir que en este estudio (día 15) solo los tratamientos $\mathrm{T}_{3}, \mathrm{~T}_{4}$ y $\mathrm{T}_{5}$ (con $10 \%, 15 \%$ y $20 \%$ de

Tabla 3. pH de los tratamientos en el tiempo.

\begin{tabular}{cccccc}
\hline Tratamiento & Día 0 & Día 5 & Día 10 & Día 15 & Día 20 \\
\hline $\mathrm{T}_{0}$ & $3,86 \mathrm{~b}$ & $3,78 \mathrm{c}$ & $3,88 \mathrm{c}$ & $3,86 \mathrm{c}$ & $3,83 \mathrm{~b}$ \\
$\mathrm{~T}_{1}$ & $4,70 \mathrm{a}$ & $4,68 \mathrm{a}$ & $4,58 \mathrm{a}$ & $4,47 \mathrm{a}$ & $4,19 \mathrm{a}$ \\
$\mathrm{T}_{2}$ & $4,69 \mathrm{a}$ & $4,56 \mathrm{a}$ & $4,54 \mathrm{a}$ & $4,44 \mathrm{a}$ & $4,25 \mathrm{a}$ \\
$\mathrm{T}_{3}$ & $4,63 \mathrm{a}$ & $4,37 \mathrm{~b}$ & $4,41 \mathrm{~b}$ & $4,31 \mathrm{ab}$ & $4,17 \mathrm{a}$ \\
$\mathrm{T}_{4}$ & $4,63 \mathrm{a}$ & $4,38 \mathrm{~b}$ & $4,35 \mathrm{~b}$ & $4,28 \mathrm{ab}$ & $4,09 \mathrm{a}$ \\
$\mathrm{T}_{5}$ & $4,50 \mathrm{a}$ & $4,50 \mathrm{~b}$ & $4,27 \mathrm{~b}$ & $4,21 \mathrm{~b}$ & $4,07 \mathrm{a}$ \\
\hline
\end{tabular}

Cifras con letras diferentes en las columnas indican diferencias significativas entre tratamientos, según test de Tamhane $(\mathrm{p} \leq 0,05)$.

Tabla 4. Acidez de los tratamientos en el tiempo.

\begin{tabular}{cccccc}
\hline Tratamiento & Día 0 & Día 5 & Día 10 & Día 15 & Día 20 \\
\hline $\mathrm{T}_{0}$ & $3,47 \mathrm{a}$ & $3,91 \mathrm{a}$ & $3,45 \mathrm{ab}$ & $4,09 \mathrm{ab}$ & $4,14 \mathrm{a}$ \\
$\mathrm{T}_{1}$ & $2,70 \mathrm{~b}$ & $3,07 \mathrm{c}$ & $3,14 \mathrm{~b}$ & $3,48 \mathrm{~b}$ & $4,12 \mathrm{a}$ \\
$\mathrm{T}_{2}$ & $2,64 \mathrm{~b}$ & $3,16 \mathrm{abc}$ & $3,30 \mathrm{ab}$ & $3,22 \mathrm{~b}$ & $3,88 \mathrm{a}$ \\
$\mathrm{T}_{3}$ & $3,16 \mathrm{ab}$ & $3,54 \mathrm{abc}$ & $3,76 \mathrm{a}$ & $3,73 \mathrm{~b}$ & $4,60 \mathrm{a}$ \\
$\mathrm{T}_{4}$ & $3,04 \mathrm{ab}$ & $3,44 \mathrm{abc}$ & $3,48 \mathrm{ab}$ & $3,16 \mathrm{~b}$ & $4,42 \mathrm{a}$ \\
$\mathrm{T}_{5}$ & $3,27 \mathrm{a}$ & $3,56 \mathrm{ab}$ & $3,61 \mathrm{ab}$ & $4,72 \mathrm{a}$ & $4,82 \mathrm{a}$ \\
\hline
\end{tabular}

Cifras con letras diferentes en las columnas indican diferencias significativas entre tratamientos, según test de Tukey $(\mathrm{p} \leq 0,05)$. 
inóculo, respectivamente) estaban dentro del rango descrito por Asís (2001).

Se puede observar que el $\mathrm{T}_{4}$ (15\% de inóculo) fue el que más disminuyó (4,63 al inicio y 4,09 como $\mathrm{pH}$ final), seguido de cerca por $\mathrm{T}_{5}$ con un $\mathrm{pH}$ final de 4,07. Reducciones atribuidas a la actividad de las bacterias ácido lácticas que se añaden con la miel del estómago al polen (Vásquez y Olofsson, 2009). Sin embargo, los valores son muy distintos a lo reportado por Silvia et al. (2008) y DeGrandi-Hoffman et al. (2013), quienes en pan de abejas obtuvieron $\mathrm{pH}$ con valores más ácidos a los obtenidos en este estudio, incluyendo al pan de abejas de colmena usado como inóculo. Esta diferencia se explica en parte por la composición del pan de abejas, el que depende de la fuente floral utilizada, de la temporada y de los factores ambientales (Baltrusaityte et al., 2007). Sin embargo, la disminución del pH durante el proceso fermentativo permite inhibir el desarrollo de microorganismos indeseables, incrementando también la producción de ácidos grasos volátiles, lo que confiere al producto un olor agradable (Villalobos, 2003).

\section{Acidez titulable}

El análisis estadístico para la acidez presenta diferencias estadísticamente significativas $(\mathrm{p} \leq 0,05)$ (Tabla 4). Para la primera medición (día 0 ) $\mathrm{T}_{0} \mathrm{y}_{5}$ presentan el mayor promedio de acidez en relación con $\mathrm{T}_{1}$ y $\mathrm{T}_{2}$. Análogamente con lo ocurrido en el caso del $\mathrm{pH}$, se observa que al inicio del ensayo los grupos son relativamente homogéneos; presentando diferencia significativa al transcurrir el tiempo, sin embargo, al final del proceso todos los tratamientos no presentan diferencias estadísticas, pero en general se aprecia un aumento del contenido de acidez titulable, lo que coincide con Loper et al. (1980), quienes señalan que la acidez titulable aumenta durante la conversión en pan de abejas. Esto se debe a que, sin importar la cantidad de inóculo, al pasar el tiempo las bacterias irán reproduciéndose y ocupando el sustrato existente (Dustmann, 2007), y al final de la evaluación (día 20) los tratamientos que al inicio tenían menos inóculo, habrán llegado a tener la misma cantidad de bacterias que los otros tratamientos tuvieron al inicio, esto se puede comparar con la elaboración del pan en el proceso de fermentación (García y Navarro, 2007). Por lo tanto, es factible elaborar pan de abejas a partir de sus elementos constitutivos, lo que se comprueba con la mayoría de los tratamientos a lo largo del tiempo, ya que se obtuvieron resultados similares al producto natural elaborado por estas.

\section{Materia seca (MS)}

En todos los tratamientos se observa un aumento en la cantidad de humedad contenida en las muestras (Tabla 5) de entre $5 \%$ y $1 \%$, lo que refleja que las muestras absorbieron humedad ambiental al momento en que los frascos fueron abiertos con el fin de extraer muestras para analizar $\mathrm{pH}$ y acidez durante el ensayo, exceptuando a $\mathrm{T}_{5}$, que perdió alrededor de $1 \%$ de humedad, donde el aumento de volumen refleja, según Human y Nicolson (2006), la adición de néctar y las secreciones glandulares de las abejas. Sin embargo, el proceso de secado debe realizarse cuidadosamente para evitar perder las propiedades nutricionales del pan de abejas, debido a la demodulación de proteínas y la inactivación de enzimas causadas por el calentamiento excesivo (Akhmetova et al., 2012).

\section{Cenizas}

Las cenizas corresponden a la fracción de la muestra que no se incineró en la mufla a $550{ }^{\circ} \mathrm{C}$, son los minerales contenidos en la muestra; los que tienen gran importancia en la dieta a pesar de

Tabla 5. Análisis bromatológico.

\begin{tabular}{ccccccc}
\hline \multirow{2}{*}{ Tratamiento } & \multicolumn{2}{c}{ \% Materia seca } & \multicolumn{2}{c}{ \% Cenizas } & \multicolumn{2}{c}{ Proteína cruda } \\
\cline { 2 - 7 } & Día 0 & Día 20 & Día 0 & Día 20 & Día 0 & Día 20 \\
\hline $\mathrm{T}_{0}$ & 76,61 & 71,39 & 2,51 & 2,66 & 21,85 & 24,17 \\
$\mathrm{~T}_{1}$ & 82,31 & 78,52 & 2,67 & 3,08 & 28,53 & 29,73 \\
$\mathrm{~T}_{2}$ & 81,87 & 78,1 & 2,32 & 3,03 & 26,03 & 31,14 \\
$\mathrm{~T}_{3}$ & 81,23 & 79,7 & 2,71 & 3,2 & 26,11 & 30,62 \\
$\mathrm{~T}_{4}$ & 80,31 & 77,35 & 2,55 & 3,1 & 24,57 & 25,57 \\
$\mathrm{~T}_{5}$ & 78,99 & 80,22 & 2,44 & 3,11 & 27,52 & 26,07 \\
\hline
\end{tabular}


necesitarse en pequeñas cantidades, debido a que cada uno de ellos tiene una función específica en el metabolismo, y por consiguiente en la mantención de la homeostasis (Cañas, 1998). El pan de abejas contiene aproximadamente $3 \%$ de minerales (cenizas) (Nagai et al., 2004), valores similares a lo reportado por Herbert y Shimanuki (1978), quienes obtuvieron valores de cenizas en polen de $3,17 \%$ comparado con el pan de abejas que fue de $2,76 \%$, indicando que el pan de abejas contiene niveles más altos debido a la adición de la miel. En relación con las cenizas Asís (2001) menciona para este parámetro valores de $2,4 \%$ y $6,4 \%$ en polen. Este autor da cifras que difieren ligeramente entre sí, pero que al mismo tiempo están en los rangos encontrados en el ensayo (Tabla 5). En tanto, Silvia et al. (2008) reportaron $3,8 \%$ y $4,2 \%$ de cenizas en pan de abejas de una mezcla de flores y girasol, respectivamente, mientras que en polen no obtuvieron valores para este parámetro. Sin embargo, Human y Nicolson (2006) reportaron que el contenido de cenizas es significativamente menor en polen almacenado que en polen fresco.

Loper et al. (1980) exponen que la concentración de minerales en el pan de abejas disminuye a medida que el polen corbicular almacenado en las celdillas se acidifica, esto probablemente refleja la adición de material lipídico por parte de las abejas. Por esta razón se hace necesario conocer las proporciones y características de los elementos que las abejas adicionan a este producto que son propios de su biología, para así obtener la correcta formulación de este producto.

\section{Proteína cruda}

La serie de procesos químicos que sufre el polen con miel para convertirse en pan de abejas aumentan su valor nutricional y disponibilidad de las proteínas (Nagai et al., 2004), por lo tanto, la composición química del pan de abeja que contiene grandes cantidades de ácidos alifáticos insaturados ( $\alpha$-linolénico y linoleico) e hidratos de carbono digerible (fructosa y glucosa) junto con aminoácidos libres es lo que determina el alto valor nutritivo del pan de abejas (Isidorov et al., 2009).
En este sentido, Nagai et al. (2004) señalan que el pan de abejas contiene aproximadamente $20 \%$ de proteínas, en consecuencia se puede decir que todas las muestras analizadas en este estudio tienen buenos contenidos de proteína (Tabla 5). Sin embargo, si bien las proteínas del pan de abejas están más disponibles que las del polen, al seguir el método de Kjeldahl, se obtienen valores totales de proteína cruda, y no se toma en cuenta su disponibilidad para el aparato digestivo, ni la presencia y grosor de la exina presente en los granos de polen, por lo que tal vez los valores obtenidos en este estudio tendrían contenidos de proteínas algo más altos. No obstante, DeGrandi-Hoffman et al. (2013) reportaron que la concentración de proteínas en el pan de abejas es más baja que en el polen, pero la concentración de aminoácidos es mayor en pan de abejas.

Por otro lado, durante la fermentación puede ocurrir la metabolización de las proteínas por parte de especies, primordialmente del género Clostridium, degradando parte importante de la proteína y sus aminoácidos en amoniaco, aminas, amidas, ácidos grasos volátiles y otros, perdiendo consecuentemente parte de su aporte de aminoácidos a la dieta (Elizalde et al., 1996). De ocurrir esto, se habrían apreciado olores desagradables (debido a los ácidos grasos volátiles derivados de esta fermentación indeseada); los que en ningún momento se presentaron, de lo que se desprende que la degradación de proteínas por colonización de bacterias indeseadas, o no ocurrió, o aconteció en tan baja proporción respecto de las otras bacterias que su efecto no tuvo incidencia en el resultado final.

\section{Conclusiones}

Es factible elaborar pan de abejas en laboratorio a partir de los elementos constitutivos logrando parámetros similares al pan de abejas natural (porcentaje de ácido láctico, ceniza, proteína cruda en etapas iniciales del proceso fermentativo). Sin embargo, es importante conocer las proporciones y características de elementos que las abejas adicionan al pan de abejas que son propios de su biología y que pueden ser responsables de la correcta formulación de este producto. 


\section{Literatura Citada}

Akhmetova, R.; Sibgatullin, J.; Garmonov, S.; Akhmetova, L. 2012. Technology for extraction of bee-bread from the honeycomb. Procedia Engineering, 42: 1822-1825.

Asís, M.

2001. Apiterapia para todos. Editorial Ciencia y Tecnología.

La Habana, Cuba, 222 pp.

Audisio, M.C.; Terzolo, H.R.; Apella, M.C.

2004. Bacteriocin from honeybee beebread Enterococcus avium, active. Applied and Environmental Microbiology, 71 (6): 3373-3375.

Baltrusaityte, V.; Venskutonis, P.R.; Ceksteryte, V.

2007. Radical scavenging activity of different floral origin honey and beebread phenolic extracts. Food Chemistry, 101: $502-514$

Cañas, $\mathrm{R}$.

1998. Alimentación y nutrición animal. Segunda edición. Pontificia Universidad Católica de Chile. Facultad de Agronomía Colección en Agricultura. Santiago, Chile. 550 pp.

Chmielewski, W.

2006. Insect and mite pest infesting and contaminating bee bread and pollen loads. In: Second European Conference of Apidology EurBee. Bee Research Institute Dol, CZ. Prague, pp. 103-104.

Degrandi-Hoffman, G.; Eckholm, B.; Hua, M.

2013. A comparison of bee bread made by Africanized and European honey bees (Apis mellifera) and its effects on hemolymph protein titers. Apidologie, 44: 52-63.

Dustmann, J.

2007. Fresh pollen offers best therapeutic and nutritional benefits. In: $5^{\text {th }}$ German Apitherapy Congress. Passau, Germany, pp. 2.

Elizalde, F.; Hargreaves, A.; Wernik, C.

1996. Conservación de forrajes. In: Praderas para Chile. I. Ruiz. Instituto Nacional de Investigaciones Agropecuarias (INIA). Ministerio de Agricultura. Gobierno de Chile. Santiago, Chile, pp. 396-426.

García, D.; Navarro, V.

2007. Elaboraciones básicas para pastelería-repostería. Clasificación de las pastas. Técnicas de elaboración y presentación. Ideaspropias Editorial. Vigo, España, 272 pp.

Gilliam, M.; Prest, D.B.; Lorenz, B.J.

1989. Microbiology of pollen and bee bread: taxonomy and enzymology of molds. Apidologie, 20: 53-68.

Gilliam, M.; Roubik, D.W.; Lorenz, B.J.

1990. Microorganisms associated with pollen, honey, and brood provisions in the nest of a stingless bee, Melipona fasciata. Apidologie, 21: 89-97.

Hanke, F.

1998. Uso del reflectómetro RQ-Flex en análisis de suelo. Primera edición. Merck Colombia S.A. Bogotá, Colombia, 58 pp.
Herbert, E.W.; Shimanuki, H.

1978. Chemical composition and nutritive value of beecollected and bee-stored pollen. Apidologie, 9: 33-40.

Human, H.; Nicolson, S.

2006. Nutritional content of fresch, bee-collected and stored pollen of Aloe greatheadii var. Davyana (Asphodelaceae). Phytochemistry, 67: 1486-1492.

Isidorov, V.; Isidorova, A.; Sczczepaniak, L.; Czyzewska, U. 2009. Gas chromatographic-mass spectrometric investigation of the chemical composition of beebread. Food Chemistry, 115 (3): 1056-1063.

Loper, G.M.; Standifer, L.N.; Thompson, M.J.; Gilliam, M. 1980. Biochemistry and microbiology of bee-collected almond (Prunus dulcis) pollen and bee bread: L-fatty acids, sterols, vitamins and minerals. Apidologie, 11 (1): 63-73.

Matissek, R.; Shnepel, F.; Steiner, G.

1998. Análisis de los alimentos: fundamentos, métodos, aplicaciones. Acribia, S.A. Zaragoza, España, 522 pp.

Nagai, T.; Nagashima, T.; Suzuki, N.; Inoue, R.

2005. Antioxidant activity and angiotensin I-converting enzyme inhibition by enzymatic hydrolysates from bee bread. Zeitschrift fur Naturforschung. Section C Journal of Biosciences 60: 133-138.

Nagai, T.; Nagashima, T.; Myoda, T.; Inoue, R.

2004. Preparation and functional properties of extracts from bee bread. Nahrung/Food 48 (3): 226-229.

Oliveira, G.; Serrâo, J.; Message, D.

2002. Digestibility of pollen of grains by worker honeybees, Apis mellifera (Hymenoptera, Apidae, Apini) in the microregion of Viçosa, MG, Brazil. Revista Brasileira de Zoociências, 4 (2): 193-201.

Silvia, P.; Jivan, A.; Harmanescu, M.

2008. Researches regarding the mineral content of pollen and bee bread samples rise from Banats area. Bulletin UASVM Animal Science and Biotechnologies, 65 (1-2): 447.

Stanciu, O.; Marghitas, L.A.; Dezmirea, D.

2007. Examination of antioxidant capacity of beebread extracts by different complementary assays. Bulletin USAMV-CN 63 (1-2): 204-207.

Vásquez, A.; Olofsson, T.

2009. The lactic acid bacteria involved in the production of bee pollen and bee bread. Journal Apicultural Research, 48 (3): 189-195.

Villalobos, E.

2003. Aislamiento, selección y caracterización de bacterias ácido lácticas en ensilajes de soya. Agronomía Costarricense, 27 (2): 21-27. 
